\title{
Study of Thermal and Mechanical Properties of LLDPE/Sugarcane bagasse/Eggshell Hybrid Biocomposites ${ }^{\dagger}$
}

\author{
Watcharin SITTICHAROEN*, Supachai AUKARANARAKUL \\ and Kitti KANTALUE
}

Department of Industrial Engineering, Faculty of Engineering, Rajamangala University of Technology Lanna, Chiang Mai 50300, Thailand

('Corresponding author's e-mail: wsitticharoen@hotmail.com)

Received: 23 July 2017, Revised: 29 March 2018, Accepted: 30 April 2018

\begin{abstract}
Thermal and mechanical properties of neat linear low-density polyethylene (LLDPE) hybrid biocomposite with sugarcane bagasse and eggshell as a reinforcing filler were investigated. Hybrid biocomposites with sugarcane bagasse/eggshell was varied in the range of $6 / 4,12 / 8,17 / 13,20 / 20,13 / 17$, $8 / 12$, and $4 / 6$ wt. $\%$, were prepared and examined. The sugarcane bagasse fiber ( $\mathrm{Sb}$ ) was surface-treated using a silane coupling agent (3-(trimethoxysilyl) propyl methacrylate) and eggshell (Es) was treated using titanium (IV) isopropoxide. The results showed that high calcium oxide content was $99 \%$ by weight in eggshell and silicon dioxide content was $50 \%$ by weight in sugarcane bagasse. The tensile and flexural modulus and hardness of the composites with treated $\mathrm{Sb} / \mathrm{Es}$ were higher than that of the untreated. These values of the LLDPE/Sb/Es composites increased with $\mathrm{Sb} / \mathrm{Es}$ content. Differential scanning calorimetry (DSC) results show interesting trends in term of the influence of Sb/Es content, both with untreated and treated $\mathrm{Sb} /$ Es on the crystallization behavior of the composites but the melting and cold crystallization temperature of its composites did not obviously change. Thermogravimetric analysis (TGA) indicated their thermal stability of the composites, both untreated and surface-treated Sb/Es were lower than that of neat LLDPE. The sample molded from the biocomposite with surface-treated $\mathrm{Sb} / \mathrm{Es}$ particles showed better dispersion of the materials inside.
\end{abstract}

Keywords: Sugarcane bagasse, eggshell, linear low-density polyethylene, thermal properties, mechanical properties

\section{Introduction}

Many researches have great concern in the development and application of biocomposites due to the risks of the petroleum-derived product [1-4]. Therefore, natural fiber reinforced in polymer composites have received increasing attention by important industries such as automotive, construction and packaging industry. Sugarcane bagasse is a fibrous residue left from extraction of the juice from the sugarcane within the sugar mill. Due to the high production of sugar, the volume of sugarcane bagasse has become large approximately 1,580 million dry tons produced annually in Thailand [5], and at present, sugarcane bagasse has been adopted and used in the manufacture of pulp and paper articles as well as in building material applications and used as a filler in polymeric materials. Mulinari et al. [6] studied the effect of chemical modification of sugarcane bagasse cellulose with zirconium oxychloride on mechanical

\footnotetext{
${ }^{\dagger}$ Part of this work was presented at the $9^{\text {th }}$ International Conference on Sciences, Technology and Innovation for Sustainable Well-Being, China: June 26-28, 2017
} 
http://wjst.wu.ac.th

properties of high-density polyethylene (HDPE) composites, and found that the tensile strength of the composites with modified sugarcane bagasse cellulose was higher than that of the non-modified. Luz et al. [7] found that polypropylene (PP) composites reinforced with cellulose fibers from sugarcane bagasse increased the flexural strength and modulus, and differential scanning calorimetry (DSC) results revealed that the composites reinforced with untreated cellulose fibers were more crystalline than that of neat PP. Ashori et al. [8] found that bagasse/HDPE composites reinforced with multi-walled carbon nanotubes (MWCNTs) increased the tensile and flexural properties. Lei et al. [9] found that a recycled high-density polyethylene (RHDPE) filled with a maleated surface-treated bagasse fiber significantly improved their compatibility between the bagasse fiber and RHDPE. Chicken eggshells are food industrial by-products that have been considered waste and are disposed in landfills which may causes environmental problem. Each year in the US, hundreds of thousands of tons of chicken eggshells are disposed in landfills [10]. Researchers have reported several attempts to use eggshell for different applications [11-13]. Eggshell was utilized as coating pigments for inkjet printing paper [14]. Eggshell can also be considered as a potential source of bio-fillers that can be efficiently used to improve their properties of polymer composites. Boronet et al. [15] suggested that high calcium oxide content of $97.7 \%$ by weight in eggshell and found that the modified eggshell improved stiffness, hardness, flexural and tensile modulus of the high-density polyethylene biocomposites. Bootklad et al. [16] found that eggshell powder acted as a coupling agent and improved the interaction between the eggshell powder and the thermoplastic starch matrix. Hybrid composite is a combination of filler particles and fibers in a polymer matrix. The influence of filler particles and fibers was evaluated by scientists and engineers because of its effect on the mechanical properties of the polymer composites [17-19]. Senturk et al. [20] studied the effect of calcite/short glass fiber (SGF) on thermal and mechanical properties of polypropylene hybrid composites, and found that the increasing in the calcite and SGF content increased melting and decomposition temperatures, and also enhanced the tensile and bending properties. Silva et al. [21] found that the tensile strength and tensile modulus of epoxy resin hybrid composites increased with increasing the volume faction of sisal fibres was $30 \%$, and silica microparticles and maleic anhydride addition.

The aim of this study is to develop biocomposites material made from linear low-density polyethylene filled with surface-treated sugarcane bagasse and eggshell as bio-filler.

\section{Materials and methods}

\section{Raw materials}

Linear low-density polyethylene (LLDPE) with a melt flow rate of $7 \mathrm{~g} / 10 \mathrm{~min}$ was used as received and was supplied in the form of LLDPE powder by Thai Polyethylene Co., Ltd. (Bangkok, Thailand). Sugarcane bagasse ( $\mathrm{Sb}$ ) was kindly supplied by local sugarcane juice shop (Chiang Mai, Thailand). Sugarcane bagasse was washes and dried, then spinning-cut with a high speed mixer (High speed mixer machine, HF800-A) and sieved (Stainless steel sieve, ASTM-E11 No. 270 mesh). The Sugarcane bagasse powder was dried in an oven for $24 \mathrm{~h}$ at $100{ }^{\circ} \mathrm{C}$. The average particle size of the Sb used was $53 \mu \mathrm{m}$. Eggshell (Es) was obtained from brown eggs kindly supplied by Irin bakery (Chiang Mai, Thailand). Eggshell was washes and dried, then grinded and sieved (Stainless steel sieve, ASTM-E11 No. 270 mesh). The eggshells powder was dried in an oven for $24 \mathrm{~h}$ at $100{ }^{\circ} \mathrm{C}$. The average particle size of the Es used was $53 \mu \mathrm{m}$. The particle size of $\mathrm{Sb}$ and Es shown in Table 1 were determined using a particle size analyzer (Malvern, Mastersizer-S, UK). In order to analyze the obtained composites a complete characterization of the $\mathrm{Sb}$ and Es particles has been carried out. The chemical compositions of the Es and $\mathrm{Sb}$ particles listed in Table $\mathbf{2}$ were determined by means of X-ray fluorescence spectroscopy (XRF, MESA-500W, Horiba, Japan).

\section{Surface treatment of $\mathrm{Sb}$}

A solution of $3.0 \mathrm{wt} \% \%$ silane coupling agent (3-(trimethoxysilyl) propyl methacrylate) was prepared and slowly added into $100 \mathrm{ml}$ of ethanol. After stirring for $15 \mathrm{~min} .100 \mathrm{~g}$ of the Sb particles were then mixed into the solution and stirred for $15 \mathrm{~min}$ to obtain a uniform distribution of the coupling agent on the $\mathrm{Sb}$ surfaces. After surface treatment, the Sb particles were dried in an oven for $24 \mathrm{~h}$ at $100{ }^{\circ} \mathrm{C}$. 
http://wjst.wu.ac.th

Table 1 Particle size distribution of sugarcane bagasse and eggshell particles.

\begin{tabular}{|c|c|c|}
\hline \multirow{2}{*}{ Particle size distribution $(\mu \mathrm{m})$} & \multicolumn{2}{|c|}{ Content (\%) } \\
\hline & $\mathbf{S b}$ & Es \\
\hline$<37$ & 44.91 & 45.23 \\
\hline $37-44$ & 10.42 & 10.42 \\
\hline $44-53$ & 12.22 & 12.17 \\
\hline $53-63$ & 10.98 & 10.90 \\
\hline $63-74$ & 8.53 & 8.45 \\
\hline $74-88$ & 6.85 & 6.78 \\
\hline $88-105$ & 4.44 & 4.40 \\
\hline$>105$ & 1.65 & 1.64 \\
\hline
\end{tabular}

Table 2 Chemical composition of the sugarcane bagasse and eggshell particles.

\begin{tabular}{cc}
\hline Investigation of chemical composition XRF (Sugarcane bagasse particles) & Content (\%) \\
\hline Silicon dioxide $\left(\mathrm{SiO}_{2}\right)$ & 50.041 \\
Sulfur trioxide $\left(\mathrm{SO}_{3}\right)$ & 20.385 \\
Phosphorus $(\mathrm{V})$ oxide $\left(\mathrm{P}_{2} \mathrm{O}_{5}\right)$ & 14.883 \\
Calcium oxide $(\mathrm{CaO})$ & 10.186 \\
Iron (III) oxide $\left(\mathrm{Fe}_{2} \mathrm{O}_{3}\right)$ & 4.506 \\
\hline Investigation of chemical composition XRF (Eggshell particles) & Content (\%) \\
\hline Calcium oxide $\left(\mathrm{CaO}^{2}\right)$ & 99.027 \\
Sulfur trioxide $\left(\mathrm{SO}_{3}\right)$ & 0.750 \\
Potassium oxide $\left(\mathrm{K}_{2} \mathrm{O}\right)$ & 0.117 \\
Iron (III) oxide $\left(\mathrm{Fe}_{2} \mathrm{O}_{3}\right)$ & 0.108 \\
\hline
\end{tabular}

\section{Surface treatment of Es}

A solution of 1.0 wt.\% silane coupling agent (titanium (IV) isopropoxide) was slowly prepared and added into $100 \mathrm{ml}$ of ethanol before stirring for $15 \mathrm{~min} .100 \mathrm{~g}$ of the Es particles were then mixed into the solution and stirred for 15 min to garantee a uniform distribution of the coupling agent on the Es surfaces. After Surface treatment, the Es particles were dried in an oven for $24 \mathrm{~h}$ at $100{ }^{\circ} \mathrm{C}$.

\section{Preparation and fabrication of LLDPE/Sb/Es composites}

LLDPE powder were dry-mixed with desired amounts of $\mathrm{Sb}$, Es particles and the silane coupling agent in a high speed mixer for 3 min to obtain LLDPE/Sb/Es composite powders, which were then held in an oven at $80^{\circ} \mathrm{C}$ for $24 \mathrm{~h}$. The $\mathrm{Sb}$ and Es content was varied from 0 to $20 \mathrm{wt} . \%$. Then, LLDPE/Sb/Es composites were compression-molded at $140{ }^{\circ} \mathrm{C}$ for $1 \mathrm{~min}$ with compression force was $250 \mathrm{~kg}$ per square centimeter and cooling time with air for $1.5 \mathrm{~min}$ using a laboratory press (RMUTL TD-001) to produce test specimens for determination of their mechanical properties.

\section{Mechanical properties}

The mechanical properties of neat LLDPE and LLDPE/Sb/Es composites were evaluated via tensile, flexural, impact and hardness properties. All the mechanical property results reported in this study were averaged from at least 5 samples. The tensile test was done on a Hounsfield universal tensile machine (Model H50KS, England) at a crosshead speed of $50 \mathrm{~mm} / \mathrm{min}$ ASTM D638 (2010). The flexural test was assessed according to ASTM D790 (2007) at the test speed of $1 \mathrm{~mm} / \mathrm{min}$. The Izod impact test was 
http://wjst.wu.ac.th

conducted in accordance with ASTM D256 (1993) using a Gotech impact tester (Model GT-7045, Taiwan) with the notched side facing the pendulum. The hardness test was evaluated using a Durometer Shore D (Model HH-337-11, Japan). The test procedure was according to ASTM D2240 (2005).

\section{Scanning electron microscopy (SEM) investigations}

A fracture surface analysis is usually required to study quality of filler dispersion and interfacial adhesion between $\mathrm{Sb} / \mathrm{Es}$ filler particles and LLDPE matrix. In this work, their fracture surfaces were obtained after a 2-min immersion in liquid nitrogen. Samples were coated with gold to generate electrical conduction in the surface of the composites. The measures were performed on a JEOL (JSM-5910LV, Japan) SEM machine by applying an accelerating voltage at a $15 \mathrm{kV}$.

\section{Thermogravimetric analysis (TGA)}

Thermogravimetric analysis was used to study the thermal stabilities and degradation of the composites samples using a TG 209 F1 Libra thermogravimetric analyzer (NETZSCH, Germany). Samples with weights in the range of 5-7 $\mathrm{mg}$ were heated under a flowing nitrogen atmosphere from 30 to $700{ }^{\circ} \mathrm{C}$ at a heating rate of $10^{\circ} \mathrm{C} / \mathrm{min}$, and the corresponding mass loss was recorded.

\section{Differential scanning calorimetry (DSC)}

The melting and crystallization behavior of the polymer matrix and the composites were determined using a differential scanning calorimeter (DSC-200 F3 Maia ${ }^{\circledR}$, NETZSCH, Germany). Al1 the samples were cut into pieces weighing $6.3 \pm 0.5 \mathrm{mg}$, then sealed securely in aluminum pans, and examined in an atmosphere of nitrogen. The samples were heated from 30 to $170{ }^{\circ} \mathrm{C}$ at a heating rate of $10{ }^{\circ} \mathrm{C} / \mathrm{min}$. The enthalpies of fusion at endothermic melting temperatures $\left(\mathrm{T}_{\mathrm{m}}\right)$ were determined for all samples at the first heating scan. The degree of crystallinity $\left(\mathrm{X}_{\mathrm{c}}\right)$ of the samples was evaluated as shown in Eq. (1) $[1,9]$;

$\mathrm{X}_{\mathrm{c}}=\frac{\Delta H_{m}}{\Delta H_{0}} \times \frac{1}{W_{f}} \times 100 \%$

where $\Delta \mathrm{H}_{\mathrm{m}}$ is the enthalpy of fusion assessed from the integral area of a DSC heating curve, $\Delta \mathrm{H}_{0}$ is the enthalpy of fusion for $100 \%$ crystallinity polyethylene $(288 \mathrm{~J} / \mathrm{g})$, and $W_{f}$ is the weight fraction of the polymer matrix in the composites.

\section{Results and discussion}

\section{Characterization of Es and Sb particles}

The size distribution of Es and $\mathrm{Sb}$ particles were evaluated by using a particle size analyzer, as shown in Table 1. Their average size ranged of both particles from 37 to $63 \mu \mathrm{m}$. The chemical composition of Es and $\mathrm{Sb}$ were evaluated by using an XRF analysis. It was found that the major component of Es was $\mathrm{CaO}$, about $99.03 \%$ and the rest ones were metal oxides, whereas the major constituent of $\mathrm{Sb}$ was $\mathrm{SiO}_{2}$, about $50.04 \%$, and the rest ones were metal oxides as shown in Table 2. The morphology of Es and Sb particles are shown in Figure 1. The average particle size of the Es particles (Figure 1(a)) was slighty smaller and round shape with a relatively rough surface than that of the $\mathrm{Sb}$ particle (Figure 1(b)). 

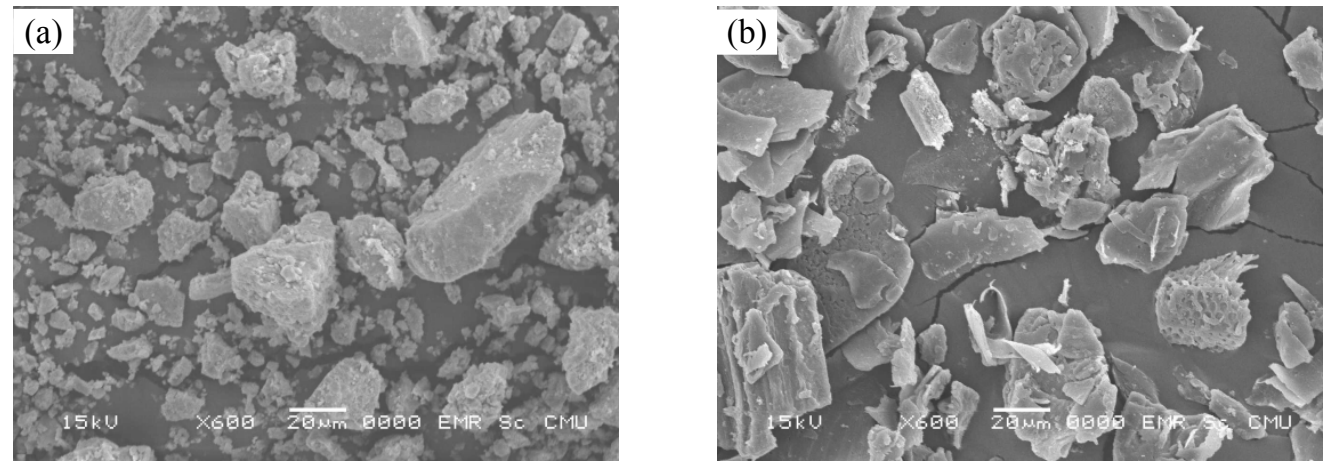

Figure 1 SEM micrographs of Es (a), and Sb (b) particles.

\section{Mechanical properties}

The average tensile modulus and flexural modulus of the LLDPE/Sb/Es composites with untreated and surface-treated $\mathrm{Sb} / \mathrm{Es}$ particles are depicted in Figure 2. As can be seen, the tensile modulus progressively increased with increasing the $\mathrm{Sb} / \mathrm{Es}$ filler content. Obviously, sugarcane bagasse fibers and calcium-based eggshell particles insertion can contribute to an increases the composite's modulus, because the Young's modulus of the Sb fibers and Es particles were higher than that of the thermoplastic modulus $[1,6,15]$. It is clearly visible that the surface-treated $\mathrm{Sb} / \mathrm{Es}$ particles presented higher tensile modulus than the untreated particles. The tensile modulus of both untreated and surface-treated $\mathrm{Sb} / \mathrm{Es}$ particles gradually increased as the filler content increased up to $20 / 20 \mathrm{wt} . \%$. The maximum tensile modulus of the composites with untreated particles was $470.1 \times 10^{6} \mathrm{~Pa}$, versus $681.4 \times 10^{6} \mathrm{~Pa}$, for surfacetreated $\mathrm{Sb} /$ Es particles. It can be seen that the flexural modulus of both untreated and surface-treated $\mathrm{Sb} /$ Es particles significantly increased as the filler content increased up to $20 / 20 \mathrm{wt} . \%$. The maximum flexural modulus of the composites with untreated $\mathrm{Sb} /$ Es particles was $687.9 \times 10^{6} \mathrm{~Pa}$, versus $859.7 \times 10^{6}$ $\mathrm{Pa}$, for surface-treated particles. The average tensile strength and flexural strength of the composites with untreated and surface-treated $\mathrm{Sb} /$ Es particles are depicted in Figure 3. Tensile strength tended to decrease when the $\mathrm{Sb} /$ Es filler loading was increased. The composites with surface-treated $\mathrm{Sb} /$ Es particles showed an improvement in tensile strength compared to the untreated. The tensile strength of the composite with 20/20 wt.\% untreated particles was $5.7 \times 10^{6} \mathrm{~Pa}$, versus $7.8 \times 10^{6} \mathrm{~Pa}$, for surface-treated $\mathrm{Sb} /$ Es particles. When the $\mathrm{Sb} / \mathrm{Es}$ filler loading was increased the flexural strength tended to decrease. The flexural strength of the composite with $20 / 20$ wt. $\%$ untreated particles was $12.8 \times 10^{6} \mathrm{~Pa}$, versus $16 \times 10^{6} \mathrm{~Pa}$, for surface-treated $\mathrm{Sb} / \mathrm{Es}$ particles. The addition of both $\mathrm{Sb}$ fibers and calcium-based eggshell particles induces the decrease of the tensile and flexural strength of the composites. The reduction in the tensile and flexural strength of the polymer composites with surface-treated $\mathrm{Sb} / \mathrm{Es}$ were likely caused by the decreasing interfacial area in LLDPE matrix as the filler concentration was increased [2,15,22]. SEM micrographs of the fracture surfaces of the LLDPE/Sb/Es composites with untreated and surface-treated $\mathrm{Sb} /$ Es particles are shown in Figure 4. Untreated particles, obvious voids and pores erose and separation between the LLDPE matrix and Sb fibers and Es particles occurred, as shown in Figures 4(a), 4(c) and 4(e) because of the incompatibility between the hydrophobic matrix and hydrophilic sugarcane bagasse and eggshell particles. The surface-treated improved significantly the compatibility between the matrix and Sb-Es particles, and the matrix was well bonded to the filler particles, as seen in Figure 4(b), 4(d) and 4(f). The surface-treated $\mathrm{Sb} /$ Es particles improved the compatibility between the LLDPE matrix and $\mathrm{Sb}$-Es particles more than the untreated particles. 
http://wjst.wu.ac.th

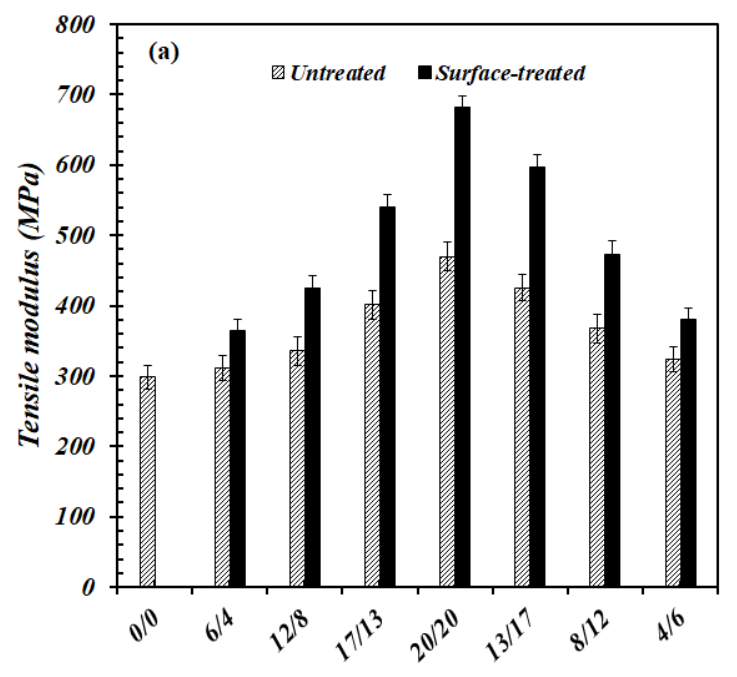

Sugarcane bagasse/Eggshell content (wt\%)

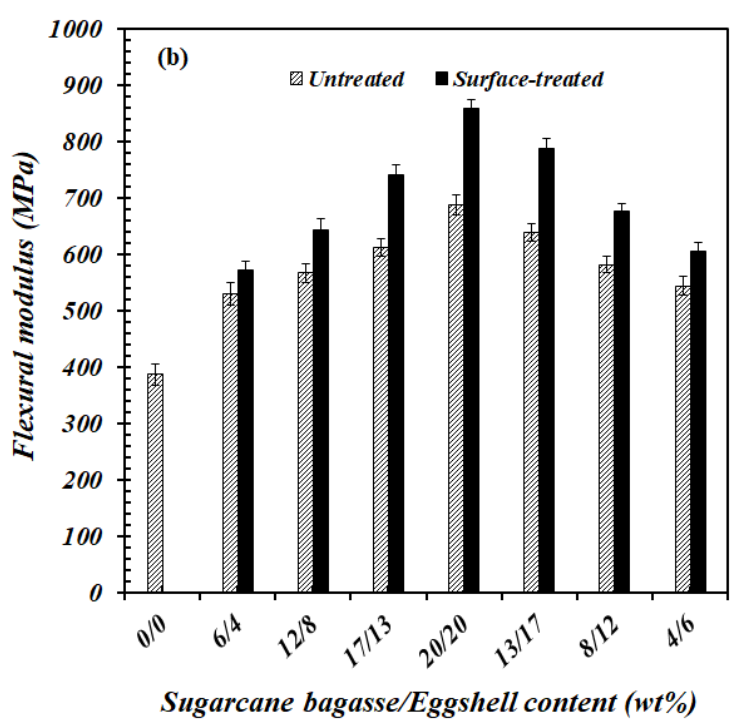

Figure 2 Effect of sugarcane bagasse/eggshell content on tensile modulus (a) and flexural modulus (b) for $\mathrm{LLDPE} / \mathrm{Sb}$ /Es composites with untreated and surface-treated $\mathrm{Sb} /$ Es particles.

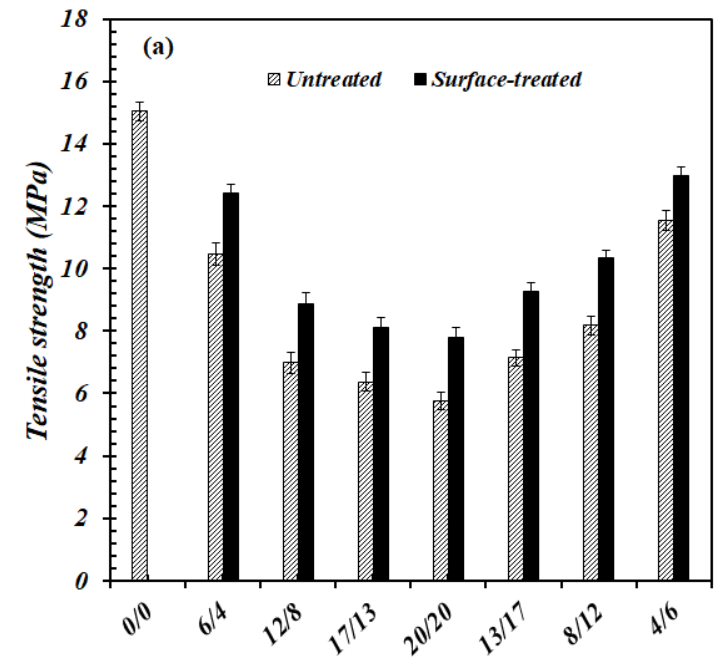

Sugarcane bagasse/Eggshell content (wt\%)

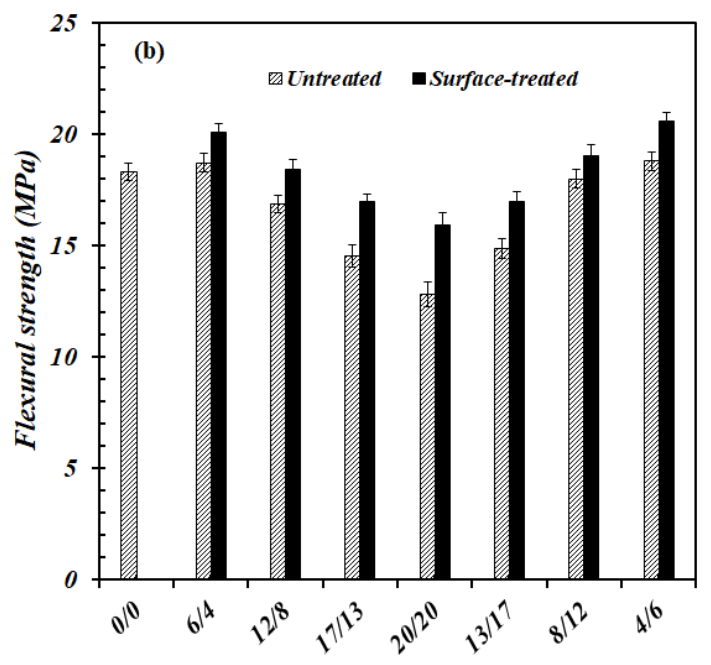

Sugarcane bagasse/Eggshell content (wt\%)

Figure 3 Effect of sugarcane bagasse/eggshell content on tensile strength (a) and flexural strength (b) for $\mathrm{LLDPE} / \mathrm{Sb} / \mathrm{Es}$ composites with untreated and surface-treated $\mathrm{Sb} /$ Es particles. 

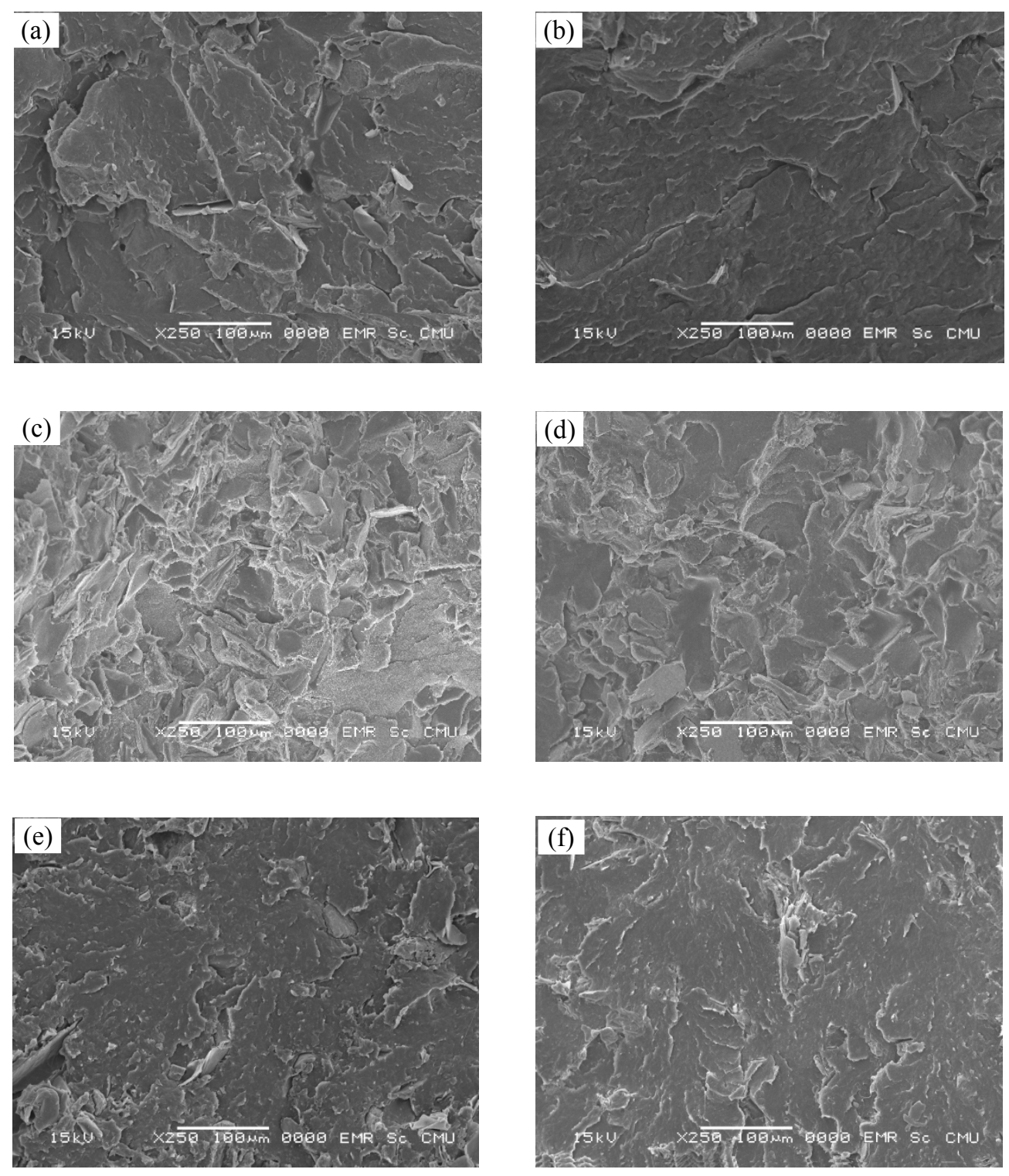

Figure 4 SEM micrographs of LLDPE/Sb/Es composites for different Sb/Es contents of untreated (a) 6/4 wt. $\%$ (c) 20/20 wt.\% (e) 4/6 wt.\% and surface-treated Sb/Es particles (b) $6 / 4$ wt.\% (d) 20/20 wt.\% (f) 4/6 wt.\%.

The average impact strength of the LLDPE/Sb/Es composites with untreated and surface-treated $\mathrm{Sb} / \mathrm{Es}$ particles is depicted in Figure 5. It is clearly visible that the impact strength decreased with $\mathrm{Sb} / \mathrm{Es}$ particles addition. An increase in the concentration of sugarcane bagasse and calcium-based eggshell particles reduces the ability of LLDPE matrix to absorb energy. The reduction in impact strength with increasing both sugarcane and eggshell filler particles loading might also be due to the decreased deformability of a rigid interface between the particles and LLDPE matrix [23]. The value of the impact strength of the composite with $20 / 20$ wt.\% untreated $\mathrm{Sb} /$ Es particles was $5.8 \mathrm{~kJ} / \mathrm{m}^{2}$, versus $7.2 \mathrm{~kJ} / \mathrm{m}^{2}$, for surface-treated particles. 
http://wjst.wu.ac.th

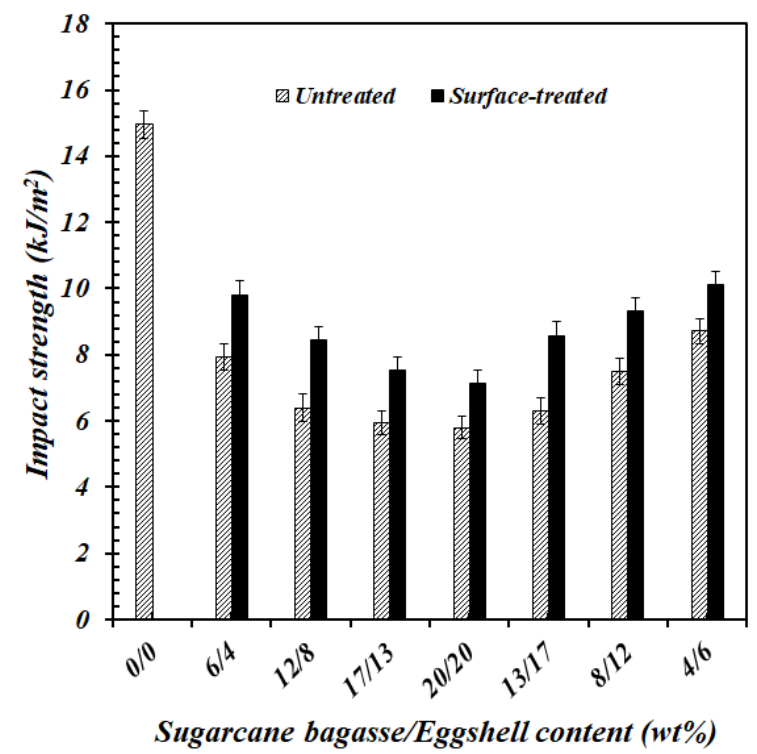

Figure 5 Effect of sugarcane bagasse/eggshell content on impact strength for LLDPE/Sb/Es composites with untreated and surface-treated $\mathrm{Sb} /$ Es particles.

Figure 6 shows the Shore D hardness of the LLDPE/Sb/Es composites with untreated and surfacetreated $\mathrm{Sb} /$ Es particles. In general, the hardness of the composites was measured on the surface of the composites, whereas the both $\mathrm{Sb}$ and Es particles were embedded dispersion on the surface and within the LLDPE matrix. The hardness values of the biocomposites increase because of greater rigidities of the both filler particles. The value of Shore hardness of the composite with 20/20 wt.\% for untreated was 56.1 , whereas those in the case with surface-treated $\mathrm{Sb} /$ Es particles was 58.

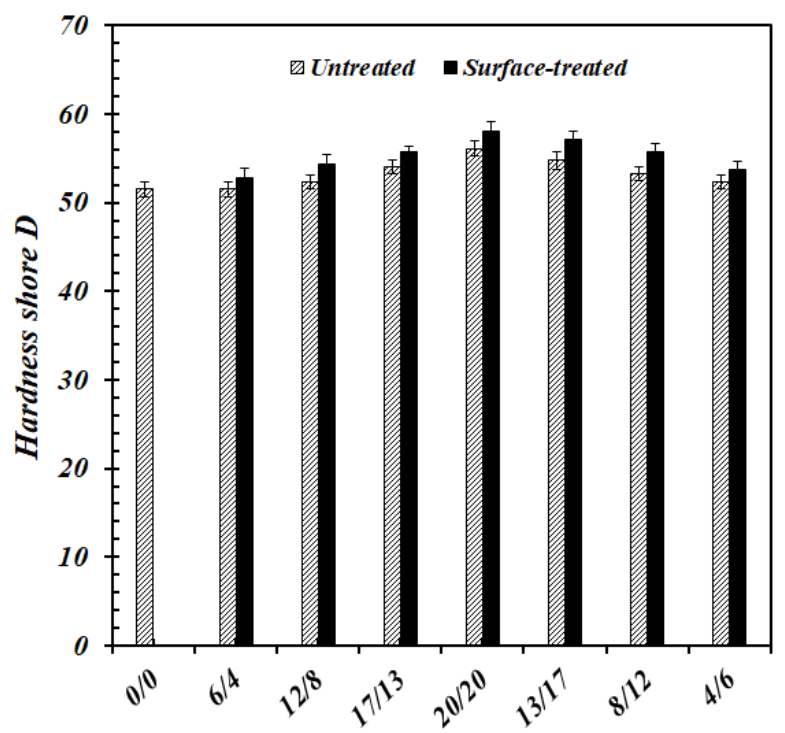

Sugarcane bagasse/Eggshell content (wt\%)

Figure 6 Effect of sugarcane bagasse/eggshell content on hardness for LLDPE/Sb/Es composites with untreated and surface-treated $\mathrm{Sb} /$ Es particles. 
http://wjst.wu.ac.th

\section{Thermal analysis}

\section{Thermogravimetric analysis (TGA)}

The weight loss of a polymer as a function of temperature can be determined by the TGA technique. It is interesting to determine the weight loss due to thermal degradation since it is an irreversible process. The typical thermogravimetric curves for neat LLDPE and LLDPE/Sb/Es composites with untreated (Figure 7(a)) and surface-treated (Figure 7(b)) Sb/Es particles are presented in Figure 7. As expected, all samples showed a major weight loss at higher temperatures in the range of $\sim 450-700{ }^{\circ} \mathrm{C}$. The results obtained showed that thermal stability of the composites, both untreated and surface-treated $\mathrm{Sb} / \mathrm{Es}$, were found to decrease with increasing the $\mathrm{Sb} /$ Es particles content and obviously the maximum difference of the thermal stability of LLDPE/Sb/Es composites observed at the filler concentration were 20/20 wt.\%. All the reported temperature values are the decomposition peak temperature obtain from the derivative TGA curves. It was found that the neat LLDPE shows only one decomposition step at $476.2{ }^{\circ} \mathrm{C}$, whereas the composites both untreated and surface-treated $\mathrm{Sb} / \mathrm{Es}$ particles presents 3 decomposition steps. The first step of the composites with 20/20 wt.\% untreated $\mathrm{Sb} / \mathrm{Es}$ particles was around $221.2-353.1{ }^{\circ} \mathrm{C}$, versus was around $222.8-353{ }^{\circ} \mathrm{C}$ for surface-treated particles, the second one with untreated $\mathrm{Sb} / \mathrm{Es}$ was at $353.1-450{ }^{\circ} \mathrm{C}$, versus was at $353-450{ }^{\circ} \mathrm{C}$ for surface-treated particles and the third step with untreated and surface-treated $\mathrm{Sb} /$ Es particles was at $450-500{ }^{\circ} \mathrm{C}$. The main weight loss both composites was between 450 and $500{ }^{\circ} \mathrm{C}$. At higher than $500{ }^{\circ} \mathrm{C}$, the weight loss became unchanged. Since, on account of the overlapping decomposition of hemicellulose and cellulose. Therefore, the first - second step can be assigned to the decomposition of hemicellulose and cellulose fiber and third corresponds to complete temperature decomposition [9,18,24]. Generally, the sugarcane bagasse fiber decomposes at a temperature of $327^{\circ} \mathrm{C}$. This observation was in line with the work of Lei et al. [9]. The thermal properties of the eggshell had been studied by the work of Hassan et al. [10] who stated that the eggshell powder showed the first step of weight loss at $310{ }^{\circ} \mathrm{C}$ due to the $\mathrm{CO}_{2}$ released after thermal degradation of the eggshell. However, it was difficult to observe an accurate position for this step because it overlapped with the major decomposition of sugarcane bagasse. It was found that all composites have a residual weight between 2.61 and $17.43 \%$, which was appeared after $500{ }^{\circ} \mathrm{C}$. Similar findings were given by the works of Luz et al. [7] studied the cellulose and cellulignin from sugarcane bagasse reinforced polypropylene composites, and found that after heating from 400 to $500{ }^{\circ} \mathrm{C}$, the degradation of cellulose was produced ash. Guimarães et al. [25] observed the characterization of sugarcane bagasse fibers and found that the final-products from degradation of sugarcane bagasse are ashes. It is clearly visible that thermal stability of the biocomposites with surface-treated $\mathrm{Sb} / \mathrm{Es}$ did not obviously different with untreated, especially at concentration of $\mathrm{Sb} / \mathrm{Es}$ particles with $20 / 20$ wt.\%.
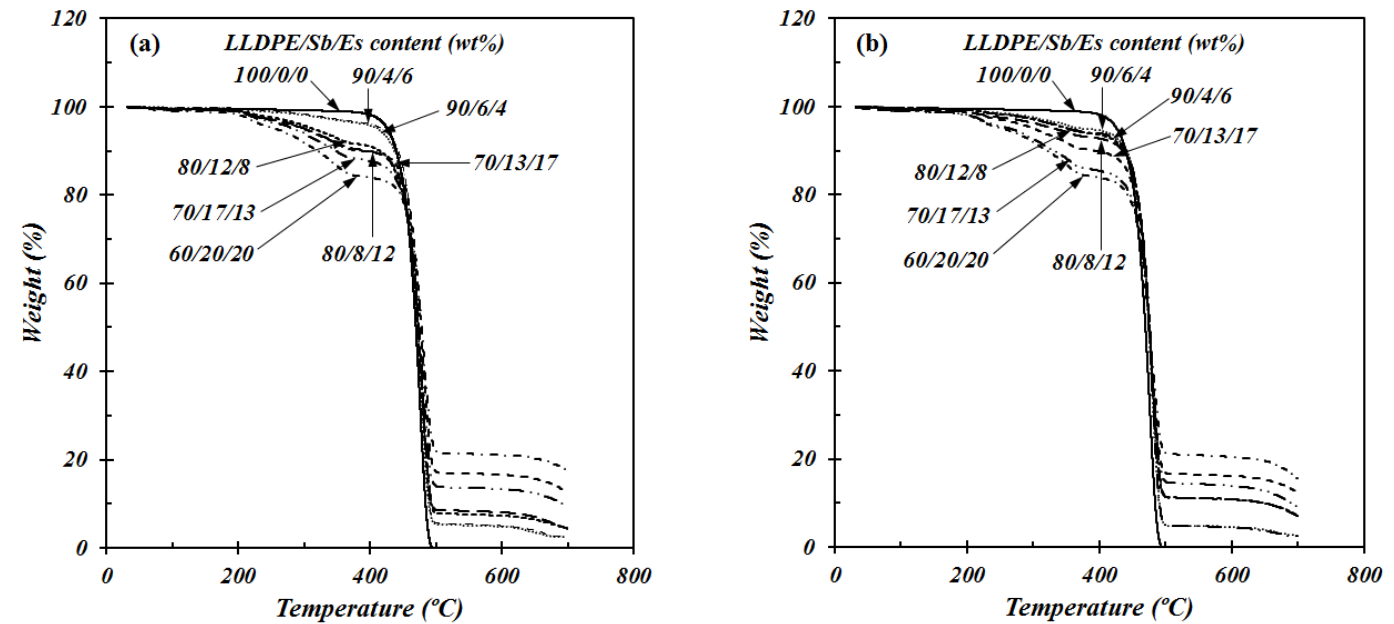

Figure 7 Thermogravimetric curves for neat LLDPE and LLDPE/Sb/Es composites of untreated (a) and surface-treated (b) $\mathrm{Sb} /$ Es particles. 
http://wjst.wu.ac.th

\section{Differential scanning calorimetry (DSC)}

DSC measurements were used to characterize the thermal properties of neat LLDPE, and LLDPE/Sb/Es composites. The results of the DSC heating thermograms are presented in Figure 8, while the numerical values of melting enthalpy, melting temperatures, cold crystallization temperatures and crystallinity for the composites are given in Table 3. It is important to note that percent crystallinity was evaluated by discounting the filler content in the different composites, as express by Eq. (1). It was found that their $\mathrm{X}_{\mathrm{c}}$ value increased progressively as the $\mathrm{Sb} / \mathrm{Es}$ filler loading was increased. It can be obviously seen that as the $\mathrm{Sb} /$ Es loading was increased, the $\mathrm{X}_{\mathrm{c}}$ value with $20 / 20 \mathrm{wt} \%$ untreated $\mathrm{Sb} / \mathrm{Es}$ particles increased $8.1 \%$, versus $9.8 \%$, for surface-treated particles. These could explain that the sugarcane bagasse and calcium-based eggshell particles acted as a nucleating agent in the LLDPE matrix, which clearly imply that although the melting and cold crystallization temperature of its composites did not obviously change with addition of $\mathrm{Sb} /$ Es filler content. The increase in crystallinity level could be supported by the work of Quan et al. [26], Sombatsompop et al. [27], and Sawpan el al. [28], who explained that cellulose fiber might act as a heterogeneous nucleating agent and nucleate crystallization along the interface, and the work of Yepes et al. [1], who described that calcium carbonate might act as nucleating agent, known as trans-crystallization phenomenon, resulting in a higher crystallinity level.
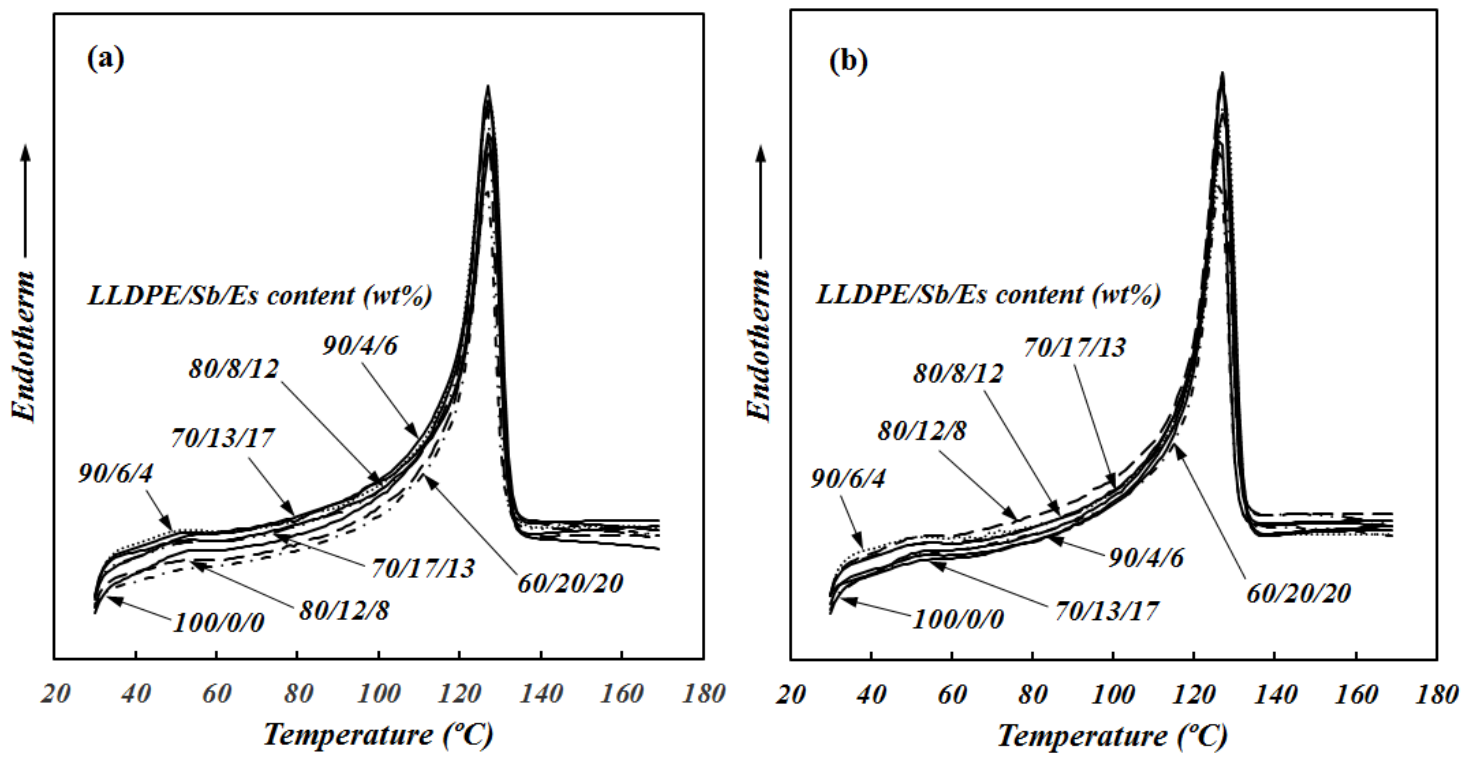

Figure 8 DSC thermograms for neat LLDPE and LLDPE/Sb/Es composites of untreated (a) and surfacetreated (b) $\mathrm{Sb} /$ Es particles. 
http://wjst.wu.ac.th

Table 3 DSC analysis for LLDPE/Sb/Es composites.

\begin{tabular}{ccccc}
\hline \multirow{2}{*}{ Sb/Es content (wt.\%) } & \multicolumn{4}{c}{ Thermal properties } \\
\cline { 2 - 4 } & $\left.\mathbf{T}_{\mathbf{m}} \mathbf{(}{ }^{\circ} \mathbf{C}\right)$ & $\mathbf{T}_{\mathbf{c}}\left({ }^{\circ} \mathbf{C}\right)$ & $\left.\Delta \mathbf{H}_{\mathbf{m}} \mathbf{( J / g}\right)$ & $\mathbf{X}_{\mathbf{c}} \mathbf{( \% )}$ \\
\hline Untreated Sb/Es particles & & & & \\
\hline $0 / 0$ & 126.9 & 111.0 & 124.8 & 43.3 \\
$6 / 4$ & 127.0 & 110.6 & 122.5 & 47.3 \\
$12 / 8$ & 127.0 & 111.0 & 110.9 & 48.1 \\
$17 / 13$ & 126.4 & 110.8 & 99.7 & 49.5 \\
$20 / 20$ & 126.3 & 111.0 & 88.9 & 51.4 \\
$13 / 17$ & 126.4 & 111.1 & 99.0 & 49.1 \\
$8 / 12$ & 127.2 & 110.6 & 113.2 & 49.1 \\
$4 / 6$ & 127.0 & 110.7 & 122.7 & 47.3 \\
\hline Surface-treated Sb/Es particles & & & & 45.5 \\
$6 / 4$ & 127.4 & 110.9 & 117.9 & 49.6 \\
$12 / 8$ & 127.0 & 111.1 & 114.2 & 53.6 \\
$17 / 13$ & 126.7 & 110.9 & 108.0 & 53.1 \\
$13 / 17$ & 126.6 & 110.5 & 91.7 & 50.5 \\
$8 / 12$ & 126.8 & 110.8 & 101.8 & 49.7 \\
$4 / 6$ & 126.9 & 110.8 & 114.5 & 46.2 \\
\hline
\end{tabular}

\section{Molded materials from the biocomposite}

Figure 9 shows the photograph for the appearance of the compressed saucer molded samples of the LLDPE/Sb/Es composites with 20/20 wt.\% of untreated (Figure 9(a)) and surface-treated (Figure 9(b)) $\mathrm{Sb} /$ Es particles. It was found that the specimen of compression molded from the biocomposite with surface-treated $\mathrm{Sb} / \mathrm{Es}$ particles showed better dispersion of the $\mathrm{Sb} /$ Es particles and embadded within LLDPE matrix, as compared to that of the untreated ones.

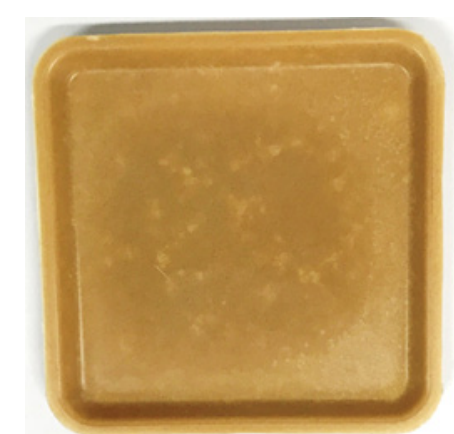

(a)

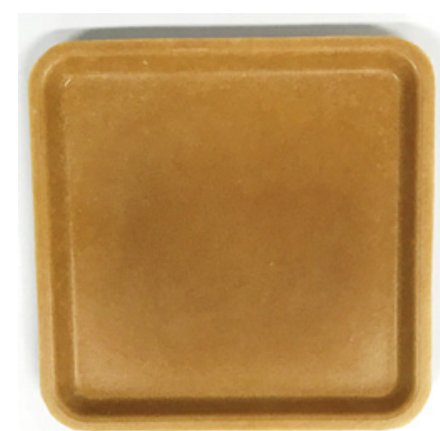

(b)

Figure 9 Appearance of compressed saucer for LLDPE/Sb/Es composites with 20/20 wt.\% of untreated (a) and surface-treated (b) Sb/Es particles. 
http://wjst.wu.ac.th

\section{Conclusions}

This study was undertaken in order to develop biocomposites material made from linear low-density polyethylene filled with surface-treated sugarcane bagasse and eggshell as bio-filler. The results indicated that high calcium oxide content was $99 \%$ by weight in eggshell and silicon dioxide content was $50 \%$ by weight in sugarcane bagasse. The tensile and flexural modulus and hardness of the composites with treated $\mathrm{Sb} / \mathrm{Es}$ were higher than that of the untreated. These values of the LLDPE/Sb/Es composites increased with $\mathrm{Sb} /$ Es content. The tensile, flexural and impact strength for both composite systems tended to decrease with increasing $\mathrm{Sb} / \mathrm{Es}$ content. The degree of crystallinity of the composites, both with untreated and treated $\mathrm{Sb} / \mathrm{Es}$ exhibited a slight increase but the melting and cold crystallization temperature of its composites did not obviously change. TGA curves showed that their thermal stability of the composites, both untreated and surface-treated $\mathrm{Sb} / \mathrm{Es}$ were lower than that of neat LLDPE. The sample molded from the biocomposite with surface-treated $\mathrm{Sb} /$ Es particles showed better dispersion of the materials inside, as compared to the untreated composite.

\section{Acknowledgements}

The authors thank the Rajamangala University of Technology Lanna (RMUTL; 2560) for financial support. Special thanks also go to Thai Polyethylene Co., Ltd. (Bangkok, Thailand) for kindly providing the raw materials.

\section{References}

[1] WU Yepes, JC Posada, LY Jaramillo and JD Sierra. Study of mechanical and physical properties of LLDPE-G-MA injection grade reinforced with coffee husk post-industrial waste. J. Compos. Mater. 2017; 51, 419-29.

[2] W Sitticharoen, A Chainawakul, T Sangkas and Y Kuntham. Rheological and mechanical properties of silica-based bagasse-fiber-ash-reinforced recycled HDPE composites. Mech. Compos. Mater. 2016; 52, 421-32.

[3] J Kajaks, Z Zelca and S Kukle. The effect of modification methods on the performance characteristics of composites based on a linear low-density polyethylene and natural hemp fibers. Mech. Compos. Mater. 2015; 51, 677-82.

[4] H Peltola, E Pääkkönen, P Jetsu and S Heinemann. Wood based PLA and PP composites: Effect of fibre type and matrix polymer on fibre morphology, dispersion and composite properties. Compos. Part A: Appl. Sci. Manuf. 2014; 61, 13-22.

[5] Office of Cane and Sugar Board. Report on Total Cane Crushing and Sugar Production 2014/2015. Thailand: Ministry of Industry, 2015.

[6] DR Mulinari, HJC Voorwald, MOH Cioffi, MLCP Da Silva and SM Luz. Preparation and properties of HDPE/sugarcane bagasse cellulose composites obtained for thermokinetic mixer. Carbohydr. Polym. 2009; 75, 317-21.

[7] SM Luz, JD Tio, GJM Rocha, AR Gonçalves and APD Arco Jr. Cellulose and cellulignin from sugarcane bagasse reinforced polypropylene composites: Effect of acetylation on mechanical and thermal properties. Compos. Part A: Appl. Sci. Manuf. 2008; 39, 1362-69.

[8] A Ashori, S Sheshmani and F Farhani. Preparation and characterization of bagasse/HDPE composites using multi-walled carbon nanotubes. Carbohydr. Polym. 2013; 92, 865-71.

[9] Y Lei, Q Wu, F Yao and Y Xu. Preparation and properties of recycled HDPE/natural fiber composites. Compos. Part A: Appl. Sci. Manuf. 2007; 38, 1664-74.

[10] TA Hassan,VK Rangari, RK Rana and S Jeelani. Sonochemical effect on size reduction of $\mathrm{CaCO}_{3}$ nanoparticles derived from waste eggshells. Ultrason. Sonochem. 2013; 20, 1308-15.

[11] YS Ok, SS Lee, WT Jeon, SE Oh, ARA Usman and DH Moon. Application of eggshell waste for the immobilization of cadmium and lead in a contaminated soil. Environ. Geochem. Health 2011; 33, 31-9. 
http://wjst.wu.ac.th

[12] H Khandelwal and S Prakash. Synthesis and characterization of hydroxyapatite powder by eggshell. J. Miner. Mater. Charact. Eng. 2016; 4, 119-26.

[13] S Wang, MH Wei and YM Huang. Biosorption of multifold toxic heavy metal ionsfrom aqueous water onto food residue eggshell membrane functionalized with ammonium thioglycolate. J.Agric. Food Chem. 2013; 61, 4988-96.

[14] S Yoo, JS Hsieh, P Zou and J Kokoszka. Utilization of calcium carbonate particles from eggshell waste as coating pigments for ink-jet printing paper. Bioresour. Tech. 2009; 100, 6416-21.

[15] T Boronat, V Fombuena, D Garcia-Sanoguera, L Sanchez-Nacher and R Balart. Development of a biocomposite based on green polyethylene biopolymer and eggshell. Mater. Des. 2015; 68, 177-85.

[16] M Bootklad and K Kaewtatip. Biodegradation of thermoplastic starch/eggshell powder composites. Carbohydr. Polym. 2013; 97, 315-20.

[17] C Fragassa, A Pavlovic and C Santulli. Mechanical and impact characterisation of flax and basalt fibre vinylester composites and their hybrids. Compos. Part B: Eng. 2018; 137, 247-59.

[18] MS Huda, LT Drzal, AK Mohanty and M Misra. The effect of silane treated-and untreated-talc on the mechanical and physic-mechanical properties of poly(lactic acid)/newspaper fibers/talc hybrid composites. Compos. Part B: Eng. 2007; 38, 367-79.

[19] M Aslan, M Tufan and T Küçükömeroğlu. Tribological and mechanical performance of sisal-filled waste carbon and glass fibre hybrid composites. Compos. Part B: Eng. 2018; 140, 241-49.

[20] O Senturk, AE Senturk and M Palabiyik. Evaluation of hybrid effect on the thermomechanical and mechanical properties of calcite/SGF/PP hybrid composites. Compos. Part B: Eng. 2018; 140, 6877.

[21] LJ da Silva, TH Panzera, VR Velloso, AL Christoforo and F Scarpa. Hybrid polymeric composites reinforced with sisal fibres and silica microparticles. Compos. Part B: Eng. 2012; 43, 3436-44.

[22] DR Mulinari, HJC Voorwald, MOH Cioffi, MLCP Da Silva, TG Da Cruz and C Saron. Sugarcane bagasse cellulose/HDPE composites obtained by extrusion. Compos. Sci. Tech. 2009; 69, 214-9.

[23] JO Agunsoye and VS Aigbodion. Bagasse filled recycled polyethylene bio-composites: Morphological and mechanical properties study. Results Phys. 2013; 3, 187-94.

[24] NR Galina, CMR Luna, GLAF Arce and I Avila. Comparative study on combustion and oxy-fuel combustion environments using mixtures of coal with sugarcane bagasse and biomass sorghum bagasse by the thermogravimetric analysis. J. Energ. Inst. 2019; 92, 741-54.

[25] JL Guimarães, E Frollini, CG da Silva, F Wypych and KG Satyanarayana. Characterization of banana, sugarcane bagasse and sponge gourd fibers of Brazil. Ind. Crops. Prod. 2009; 30, 407-15.

[26] H Quan, ZM Li, MB Yang and R Huang. On transcrystallinity in semi-crystalline polymer composites. Compos. Sci. Tech. 2005; 65, 999-1021.

[27] N Sombatsompop, A Kositchaiyong and E Wimolmala. Experimental analysis of temperature and crystallinity profiles of wood sawdust/polypropylene composites during cooling. J. Appl. Polym. Sci. 2006; 102, 1896-905.

[28] MA Sawpan, KL Pickering and A Fernyhough. Improvement of mechanical performance of industrial hemp fibre reinforced polylactide biocomposites. Compos. Part A: Appl. Sci. Manuf. 2011; 42, 310-19. 